\title{
Endoscopic ultrasound-guided transluminal drainage for aseptic splenic abscess
}

Aseptic abscesses are rare, culture-negative abscesses associated with inflammatory bowel disease which arise most commonly in solid abdominal organs including the spleen, liver, and lymph nodes $[1,2]$. Bacterial and aseptic splenic abscesses may not be treatable with antibiotics and corticosteroids alone and require drainage or splenectomy. We report successful endoscopic ultrasoundguided transmural drainage (EUS-TD) of an aseptic splenic abscess.

Our colleagues reported the case of a 41-year-old woman with ulcerative colitis complicated by pyoderma gangrenosum, multiple renal abscesses treated by percutaneous drainage, and a splenic abscess [3]. The splenic abscess measured $4 \times 4 \times 4 \mathrm{~cm}$ on imaging studies ( Fig.1). Because the splenic abscess was refractory to medications and could not be approached percutaneously, EUSTD was performed ( $\downarrow$ Video 1 ).

A forward-viewing endosonoscope (TGFUC260 J, Olympus Corp., Tokyo, Japan) was used to puncture the gastric fundus with a 19-gauge needle (EZ Shot 3 Plus, Olympus) under endosonographic and fluoroscopic guidance ( $\triangleright$ Fig.2a-d). A guidewire was advanced into the abscess and the puncture site was dilated with a biliary balloon dilator. An Uneven Double Lumen Cannula (Piolax Medical Devices, Kanagawa, Japan) was used to introduce

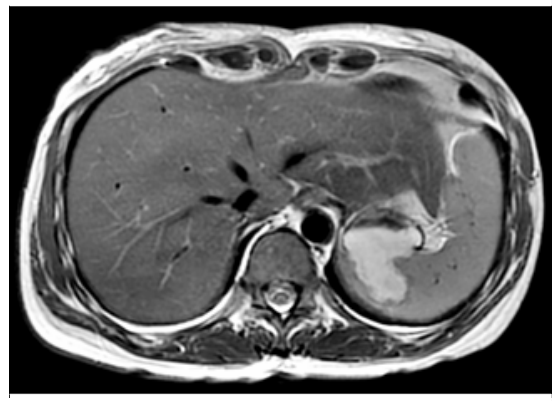

Fig. 1 T2-weighted magnetic resonance imaging revealed a hyperintense $4 \times 4 \times 4-\mathrm{cm}$ abscess in the spleen, adjacent to the gastric fundus. a second guidewire. A 4-cm, 7 Fr pigtail stent was placed over the first guidewire, while a naso-abscess drainage tube was inserted over the second guidewire
( Fig.2e,f). Follow-up abdominal ultrasound showed a shrunken abscess ( Fig.3). The naso-abscess tube was removed after cultures of the aspirate were
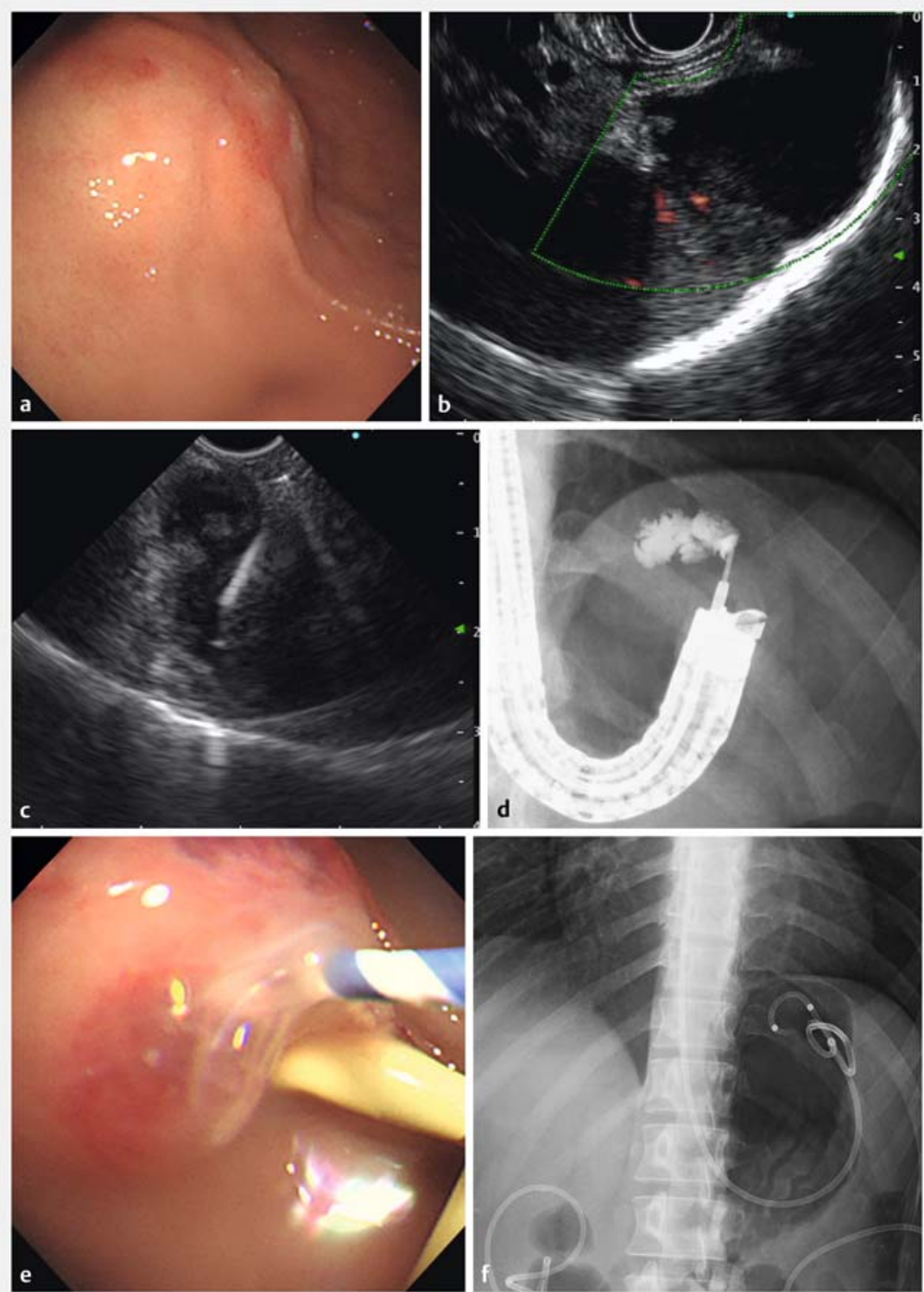

- Fig. 2 Endoscopic ultrasound (EUS)-guided transluminal drainage. a A bulge in the gastric fundus was confirmed with white light imaging with the forward-viewing endosonoscope in retroflexed position. $\mathbf{b}$ EUS revealed an anechoic abscess in the spleen. $\mathbf{c}$ Puncture with a 19-gauge needle. $\mathbf{d}$ Fluoroscopy confirmed contrast confined to a cystic structure. e A pigtail stent was placed over the first guidewire after dilation of the puncture site with a biliary balloon dilator. $\mathbf{f}$ A naso-abscess drainage tube was placed over the second guidewire. 


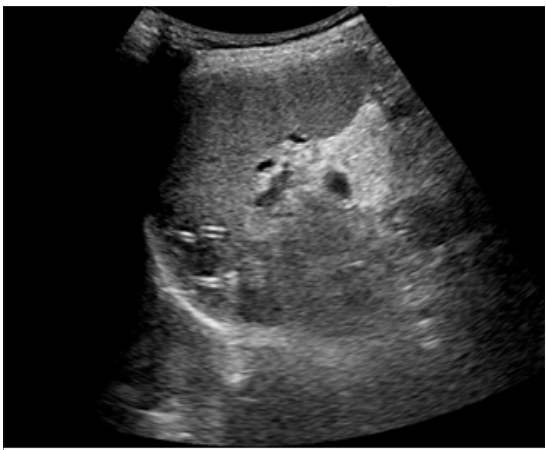

> Fig. 3 Follow-up abdominal ultrasound confirmed that the plastic stent was inside the splenic abscess with no fluid components remaining.

confirmed to be negative. No recurrence was observed during 12 months of follow-up.

There have recently been several reports of successful EUS-TD for subphrenic abscesses, including one report of EUS-TD for a splenic abscess that arose as a complication of acute pancreatitis [4,5]. EUS-TD may be an attractive option for splenic abscesses because they are often difficult to access percutaneously and are frequently refractory to medical treatment alone.

\section{Competing interests}

The authors declare that they have no conflict of interest.

The authors

Takeshi Okamoto ${ }^{1,2}$, Kenji Nakamura ${ }^{2,3}$, Katsuyuki Fukuda²

1 Department of Hepato-Biliary-Pancreatic Medicine, Cancer Institute Hospital of Japanese Foundation for Cancer Research, Tokyo, Japan

2 Department of Gastroenterology, St. Luke's International Hospital, Tokyo, Japan

3 Department of Gastroenterology, Tokyo Dental College, Ichikawa General Hospital, Chiba, Japan

\section{VIDEO}

\section{Endoscopic ultrasound-guided transluminal drainage for aseptic spl \\ ᄂ ess}

Takeshi Okamote amura MD, PhD, Katsuyuki Fukuda MD, PhD

St. Luke's International Hospital Tokyo, Japan

- Video 1 Endoscopic ultrasound-guided transluminal drainage for aseptic splenic abscess using a forward-viewing endosonoscope.

\section{Corresponding author}

\section{Takeshi Okamoto MD}

Department of Hepato-Biliary-Pancreatic Medicine, Cancer Institute Hospital of Japanese Foundation for Cancer Research, 3-8-31 Ariake, Koto, Tokyo, Japan 135-8550, Japan

Fax: +81-3-3520-0141

tak@afia.jp

\section{References}

[1] Bollegala N, Khan R, Scaffidi MA et al. Aseptic abscesses and inflammatory bowel disease: two cases and review of literature. Can | Gastroenterol Hepatol 2017; 2017: 5124354

[2] André MF], Piette JC, Kémény JL et al. Aseptic abscesses: a study of 30 patients with or without inflammatory bowel disease and review of the literature. Medicine (Baltimore) 2007; 86: 145-161

[3] Shimizu MS, Matsuo T, Mori N. A rare manifestation associated with a urinary tract infection in a patient with ulcerative colitis. Gastroenterology 2021: doi:10.1053/j.gastro.2020.12.026
[4] Morita S, Kamimura K, Suda T et al. Endoscopic ultrasound-guided transmural drainage for subphrenic abscess: report of two cases and a literature review. BMC Gastroenterol 2018; 18: 55

[5] Lee DH, Cash BD, Womeldorph CM et al. Endoscopic therapy of a splenic abscess: definitive treatment via EUS-guided transgastric drainage. Gastrointest Endosc 2006; 64: 631-633

\section{Bibliography}

Endosc Int Open 2021; 09: E1581-E1582

DOI 10.1055/a-1529-5969

ISSN 2364-3722

(c) 2021. The Author(s).

This is an open access article published by Thieme under the terms of the Creative Commons Attribution-NonDerivativeNonCommercial License, permitting copying and reproduction so long as the original work is given appropriate credit. Contents may not be used for commercial purposes, or adapted, remixed, transformed or built upon. (https:// creativecommons.org/licenses/by-nc-nd/4.0/) Georg Thieme Verlag KG, Rüdigerstraße 14, 70469 Stuttgart, Germany

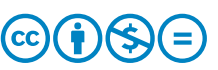

